\title{
Analysis of a cross wedge rolling process for producing drive shafts
}

\author{
Zbigniew Pater $^{1} \cdot$ Janusz Tomezak $^{1} \cdot$ Tomasz Bulzak $^{1}$
}

Received: 5 August 2016 / Accepted: 20 October 2016 / Published online: 30 October 2016

(C) The Author(s) 2016. This article is published with open access at Springerlink.com

\begin{abstract}
The paper discusses the problems of forming parts such as stepped shafts by cross wedge rolling (CWR). In industrial practice, this rolling process is performed at stages, i.e., in several passes, when large cross-sectional reductions are involved. The same can also be done using a different design of this forming process, namely, multi-wedge cross rolling (MWCR), in which the workpiece is simultaneously formed by several pairs of tools (wedges). This paper compares the above two methods with respect to forming a drive shaft. Wedge tools used in both forming processes are described, and the numerical results of the simulations performed to verify the adopted solutions are reported. The results demonstrate that the MWCR method offers more advantages than the classical CWR technique. Consequently, MWCR is then verified in experimental tests. The experimental results confirm that parts such as stepped shafts can be formed by the MWCR method.
\end{abstract}

Keywords Cross wedge rolling · Tools $\cdot$ Stepped shafts · Fem $\cdot$ Experiment

\section{Introduction}

Cross wedge rolling (CWR) is a metal forming process in which wedge-shaped tools form billet into the desired axisymmetric shape. This increasingly popular forming method is mainly used to produce stepped axes and shafts for different

Zbigniew Pater

z.pater@pollub.pl

1 Politechnika Lubelska, Lublin, Poland industrial sectors. In addition, CWR is used to produce preforms for forming elongated forgings on presses [1].

At present, there are numerous research centers which conduct research on the theory and technology of cross wedge rolling. They focus on the modeling of CWR processes by numerical methods, finding new areas of application for this method (e.g., production of toothed shafts) as well as developing solutions for making this forming process more effective (e.g., design of shorter wedge tools). In this context, it is worth drawing attention to multi-wedge cross rolling (MWCR), the process which is analyzed in this paper. To show the advantages of this method, the paper will investigate an MWCR process for producing a drive shaft, the schematic design of which is shown in Fig. 1.

\section{Survey of the research on MWCR}

Despite its numerous advantages and great potential, cross wedge rolling has certain limitations and, as a result, is not widely applied. Among others, these limitations concern the length of tools (wedges) and the resulting impossibility of forming long parts. In order to eliminate this, a new forming method has been developed. The new method, in which the material is formed by several wedges at the same time, is called multi-wedge cross rolling (MWCR). This technique can be used for producing both solid [2] and hollow parts [3].

In standard CWR processes, the wedges are described by two angles, i.e., a spreading angle, $\beta$, and a forming angle, $\alpha$. When producing a stepped shaft, individual steps of the shaft are formed one after another by the wedges which are parallel to the direction of tool displacement (Fig. 2a). On the other hand, in MCWR, the shaft is produced by all pairs of wedges at the same time, and the end wedges are additionally inclined to the rolling direction at an angle $\Theta$ (Fig. 2b). The value of $\Theta$ 


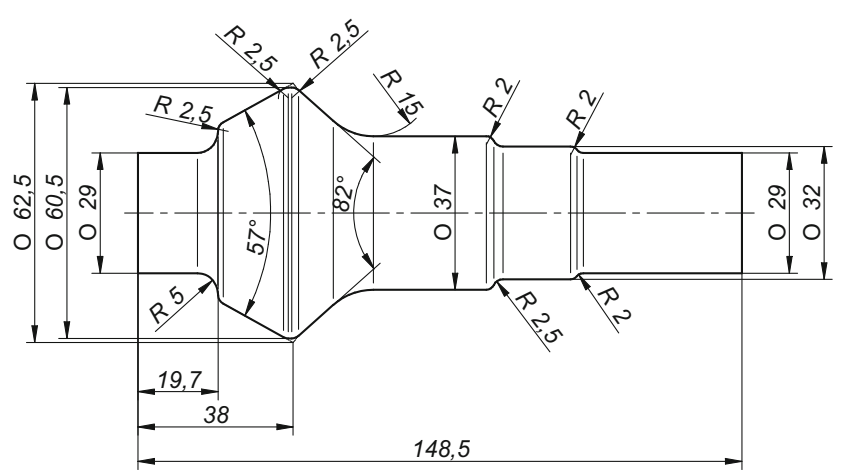

Fig. 1 Analyzed drive shaft

depends on the elongation of the workpiece due to the impact of the central wedge. The way of determining the $\Theta$ angle for the MCWR process is described in [4].

The MCWR technique can be predominantly used for producing long parts. The research and development works conducted so far have concentrated on the application of this method for producing automotive axle shafts $[2,5-7]$, stepped shafts $[4,8]$ as well as railway axles, both solid [9] and hollow [3]. In addition to this, the method can be used for forming several short parts at one time. For instance, this technique enables producing eight balls at one time, as reported in [10].

As mentioned above, MCWR offers numerous advantages. Similarly to the classical rolling process, however, the potential of the MCWR process is significantly hampered by the allowable reduction ratio. In the classical rolling process, rolling can be performed in two stages. If the MCWR process were performed in two stages,

a)

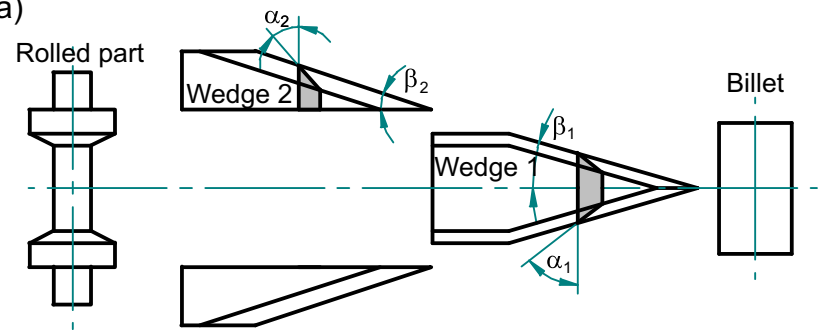

b)

Rolled part
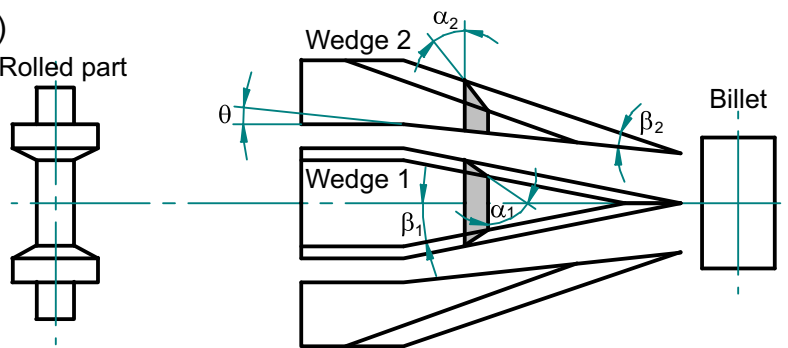

Fig. 2 Comparison: classical CWR (a) and MWCR (b)
164
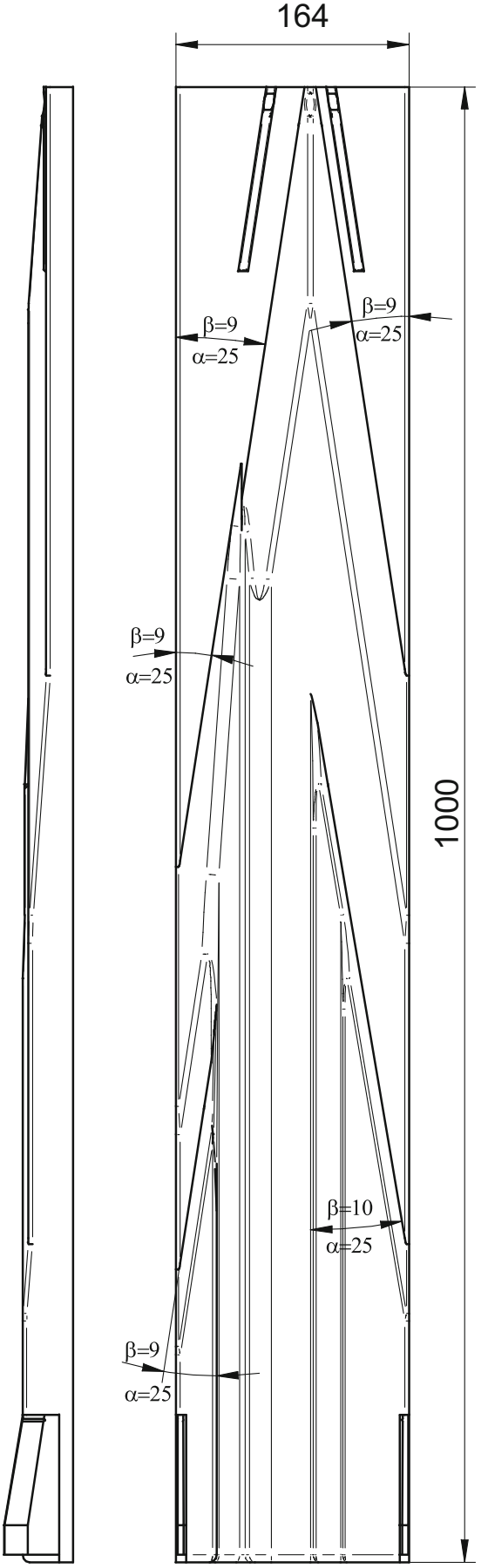

Fig. 3 Wedge for forming a single drive shaft by classical CWR

however, this would lead to elongation of the tool, which is contradictory to the essence of this process, which consists in making the tool as short as possible. The application of the two-stage rolling process prevents problems such as non-rotation of the workpiece, the occurrence of spiral grooves, and necking due to the application of too 
Fig. 4 Geometric model of the CWR process for producing a drive shaft by classical CWR

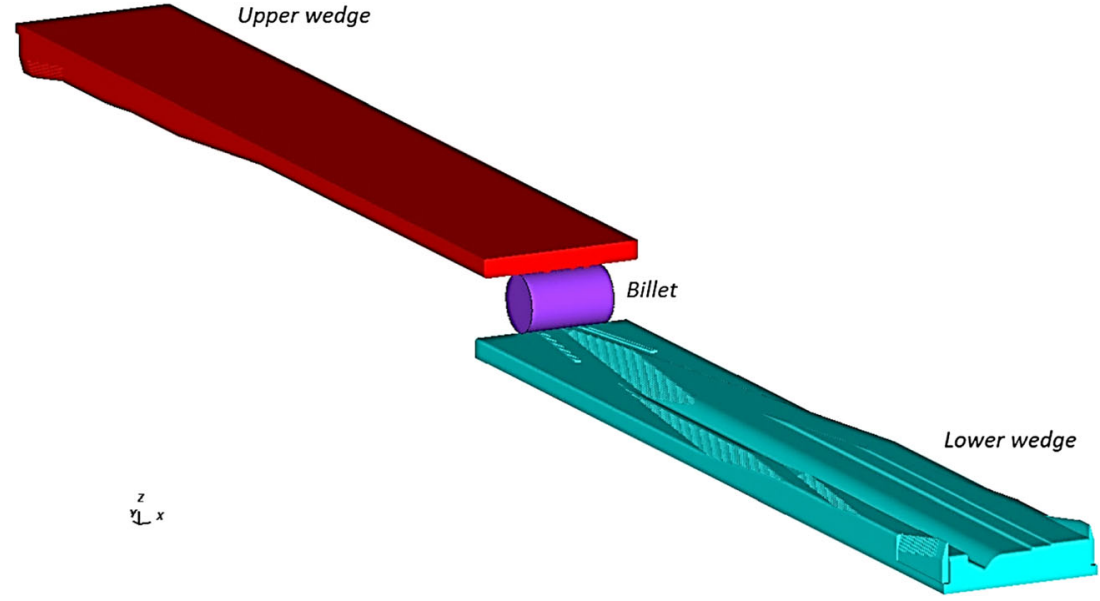

limitation or elimination of defects such as internal cracking or necking.

high reduction ratios in one pass. Jia et al. [11] demonstrate that the application of the two-stage rolling process can cause workpiece necking. According to Jia et al., the total reduction ratio in two-stage rolling should be divided equally per individual stages of the process in order to prevent workpiece necking. In their work, [12] Liu et al. demonstrate that the maximum allowable reduction ratio in cross wedge rolling should not exceed $\delta=2.0$. In turn, Li [13] showed that the application of reduction rations which are much smaller than $\delta=2.0$ can cause workpiece cracking. According to $\mathrm{Li}$, the allowable reduction ratio is a function of many variables such as the spreading angle $\beta$, the forming angle $\alpha$, the temperature of rolling, and metal grade. A significant challenge for research centers dealing with the CWR technology is to minimize failure modes resulting from the application of too high reduction ratios during rolling. It is worth pointing here to the new design of tools for cross wedge rolling, as they are provided with an additional wedge to constrain the axial flow of metal. [14]. The application of the additional wedge enables in obtaining high cross sectional reductions on a relatively short forming path, without the risk of necking or workpiece rupture.

The technological potential of the MCWR process can be increased by reversing the direction of work of the wedges in order to make them move the material from the front to the centre [15-17]. In this way, the material between the wedges can be subjected to upsetting. As the results of the study [15] demonstrates, in CWR with upsetting, the diameter of the step being formed can be increased even by $40 \%$. The application of upsetting is even more effective when wedges with smaller $\beta$ angles and larger $\alpha$ angles are used.

Although upsetting by CWR is an unconventional approach, it can lead to higher rolling efficiency due to the

\section{Classical CWR method}

The drive shaft schematically shown in Fig. 1 is characterized by a significant difference in its diameter. In the standard CWR, rolling is performed on the billet described by a diameter which is either equal to or similar to the diameter of the largest step of the shaft. Here, the diameter of the step is $58 \mathrm{~mm}$. This means that the end steps of the shaft are formed at the reduction ratio $\delta=2.0$ ( $\delta=d_{0} / d$, where $d_{0}$ is the diameter of the billet, and $d$ is the diameter of the step after rolling). Such high diameter reductions cannot be obtained by single-wedge forming $[1,11]$. For this reason, it is necessary to employ a twostage forming process, in which the end steps are first formed to an intermediate diameter of $37 \mathrm{~mm}$ $\left(\delta_{1}=1.568\right)$ and then to the target diameter $\left(\delta_{2}=1.276\right)$. Another drawback of such high plastic working of the end steps is that funnels are formed on the end-face surface of the part due to superficial metal flow. These funnels can be removed by cutting off the deformed ends of the part. Given the above, the billet should have a diameter of $58 \mathrm{~mm}$ and a length of $81.6 \mathrm{~mm}$. In the analyzed case, the billet is $215,593 \mathrm{~mm}^{3}$, while the total volume of the drive shaft is $162,635 \mathrm{~mm}^{3}$. As a result, material losses in rolling will be $52,958 \mathrm{~mm}^{3}$, which is $32.6 \%$ of the part's volume.

\subsection{Tools for CWR}

The tool segment used in the standard CWR process is shown in Fig. 3. It is assumed that the length of the tool 


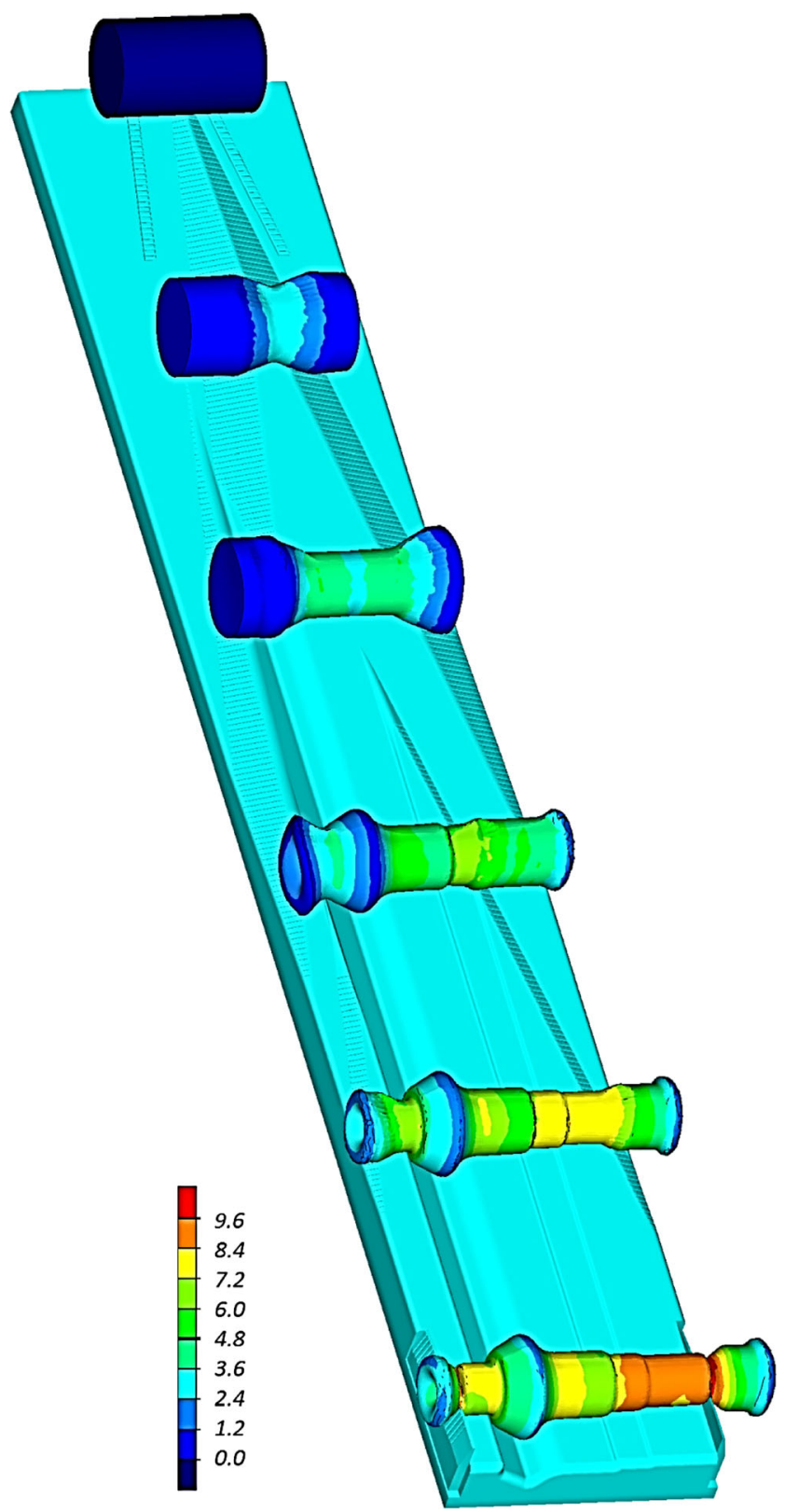

Fig. 5 Progression of the shape of drive shaft produced by the classical CWR process and the distribution of effective strain

cannot exceed $1000 \mathrm{~mm}$ (i.e., the maximum length of the tool in the rolling mill which is available at the Lublin University of Technology). According to the design of the wedge tools, all forming angles (marked as $\alpha$ ) are set to $25^{\circ}$. The values of the spreading angles $\beta$ are similar, i.e., 9 and $10^{\circ}$. At the tool ends, the cutters for cutting off end scrap material are mounted. The lateral surfaces of the wedges have technological serrations in order to prevent uncontrolled slipping.

\subsection{Numerical simulation of the CWR process}

The tool design was verified by a numerical simulation performed by the Simufact. Forming software. Shown in Fig. 4, the geometrical model of the process consists of two identical flat wedge tools and a cylindrical billet. According to the model, the only tool that moves during the forming process is the upper wedge (it moves with a velocity of $300 \mathrm{~mm} / \mathrm{s}$ ), while the lower wedge is fixed. The billet is assigned to the properties of $\mathrm{C} 45$ steel, the material model of which was obtained from the material library database of the employed software. Prior to rolling, the billet is heated to $1150{ }^{\circ} \mathrm{C}$. Other parameters applied in the simulation included the following: tool temperature $-50{ }^{\circ} \mathrm{C}$, friction factor on materialtool contact-1.0, and heat exchange coefficient $-10 \mathrm{~kW} / \mathrm{m}^{2} \mathrm{~K}$.

Fig. 5 illustrates the forming process for a drive shaft by the standard CWR method. First, a single necking with a diameter of $37 \mathrm{~mm}$ is formed in the region of the long shank. Next, the shaft is divided into steps with the same diameter in the region of the short shank. At this stage of the rolling process, some part of the material undergoes upsetting to form a shaft head described by a diameter which is higher than the diameter of the billet. Further on, end steps with the smallest diameter of $29 \mathrm{~mm}$ are formed. At the end of the process, scrap material is cut off by the side cutters. The numerical results demonstrate that the drive shaft can be produced by the classical CWR method using tools with a length of $1000 \mathrm{~mm}$.

The distribution of effective strains in the drive shaft shown in Fig. 6 is typical of cross wedge rolling processes. Specifically, the strains resemble ring-like layers, their highest values being located on external surfaces. This results from the action of friction forces which make the material flow in a circumferential direction, thus causing redundant strains.

Interesting observations can be made with respect to the variations in the damage function determined in compliance with the Cockroft-Latham criterion. A curve illustrating this function is shown in Fig. 7. It can be observed that the highest values of the function are located in the axial region of the part, i.e., near the end-face funnels. The critical areas of the damage function overlap with the end step on the short shank side of the shaft. In order to rid of this, the degree of scrap material on the left side of the shaft must be increased. This can be done by slightly shifting the billet in this direction (relative to the wedges), which will at the same time decrease the degree of scrap material on the right side of the shaft.

Fig. 8 illustrates the distribution of the temperature in the produced part. The results demonstrate that despite a relatively long forming time (approx. $6.5 \mathrm{~s}$ ), the temperature of the material remains in a hot working range. The highest drops in the temperature can be observed in the regions of the shaft which 
Fig. 6 Distribution of effective strain in a shaft produced by classical CWR
Fig. 7 Distribution of the damage function (according to Cockroft-Latham criterion) in a drive shaft produced by classical CWR
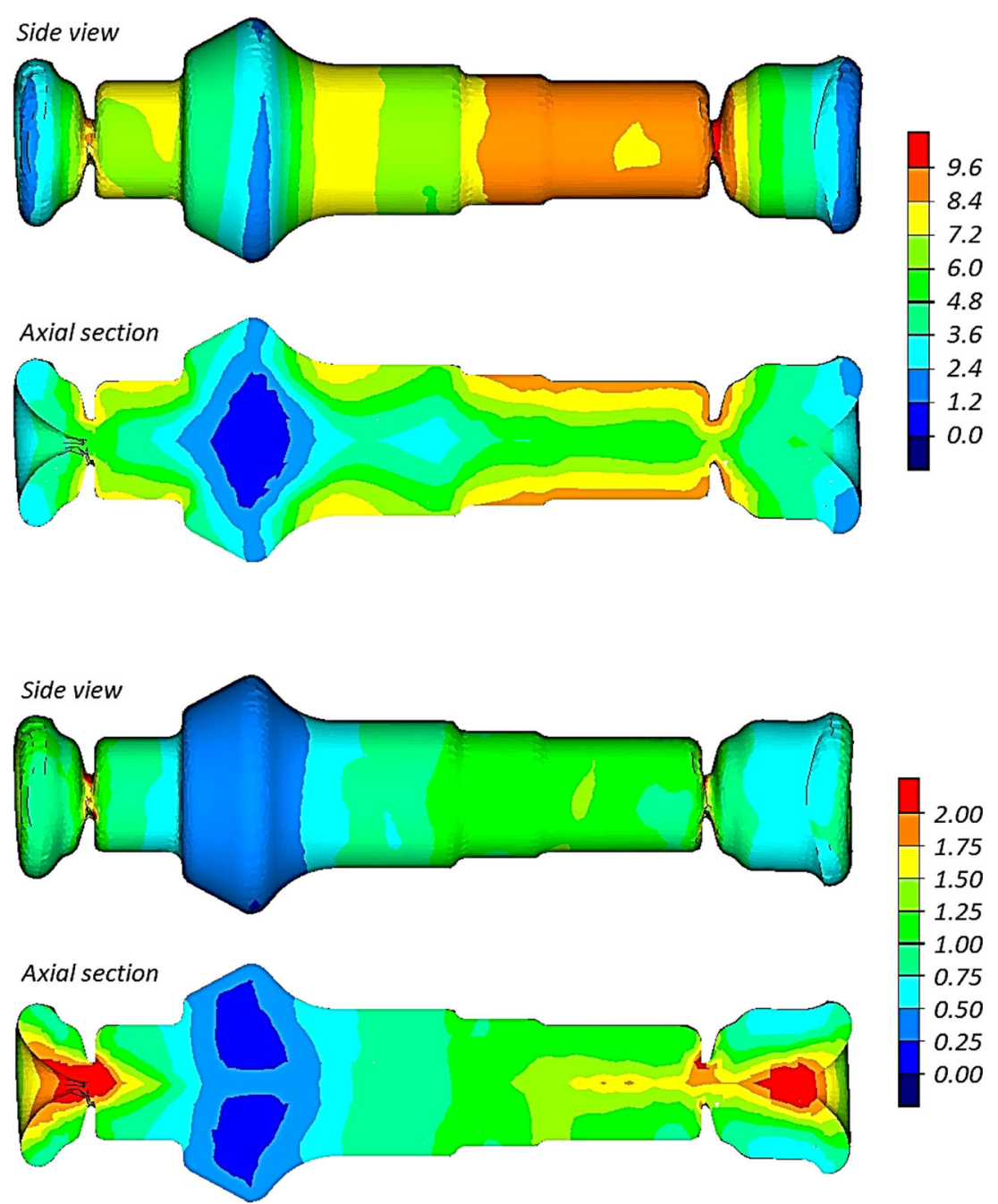

were formed first and then only remained in contact with the tools.

The application of FEM enabled determination of the forces in CWR. Figure 9 shows the distribution of the tangential force (acting on the wedge) which determines the rolling mill's power and the radial force responsible for rolling accuracy. The variations in the forces are typical of CWR processes [1]. During the forming stage, the forces gradually increase and then they decrease during the sizing of the shaft. After that, the forces increase again when they contact the material and the cutters.
Fig. 8 Distribution of the temperature (in ${ }^{\circ} \mathrm{C}$ ) in a drive shaft produced by classical CWR

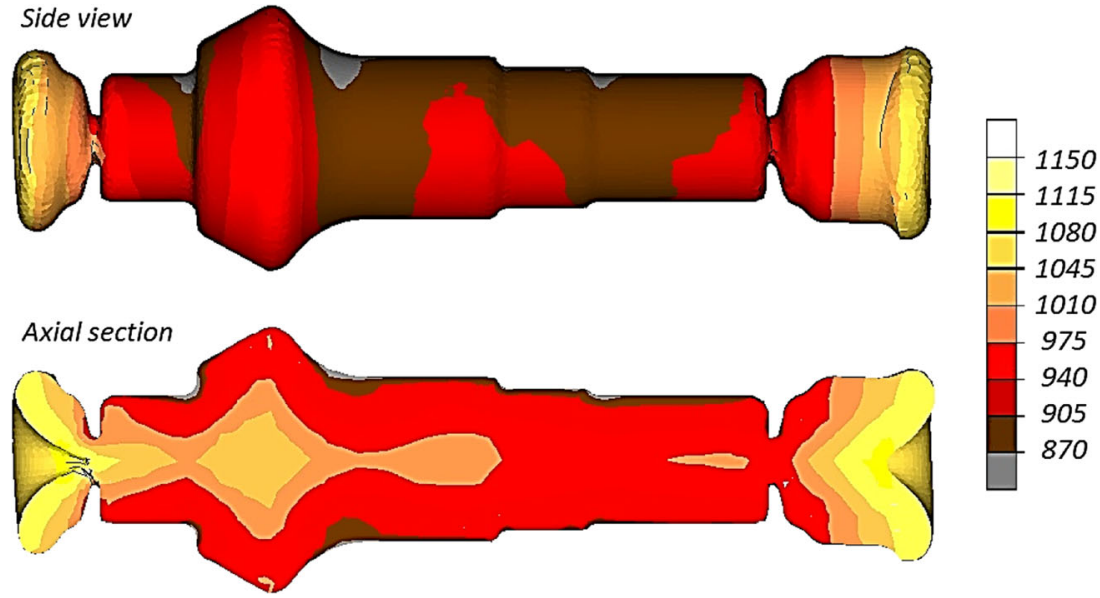




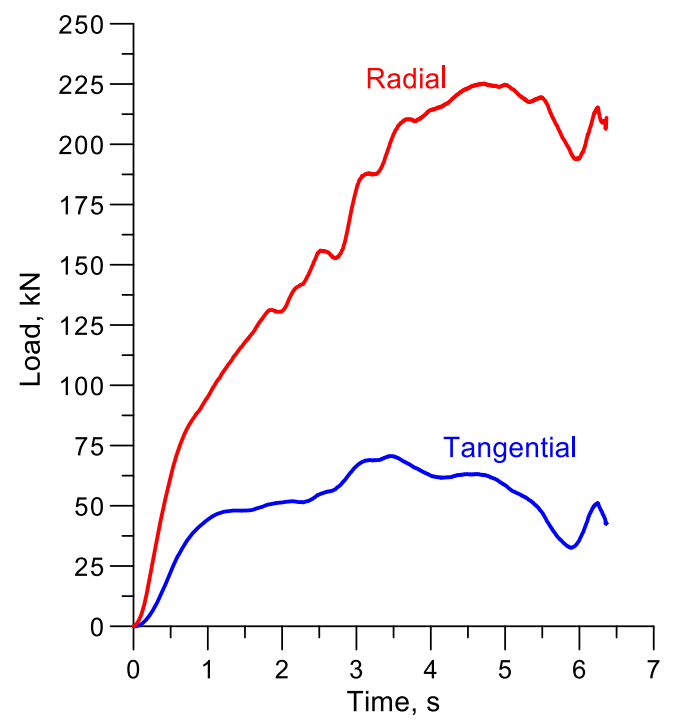

Fig. 9 Variations in the rolling forces when producing a drive shaft by classical CWR

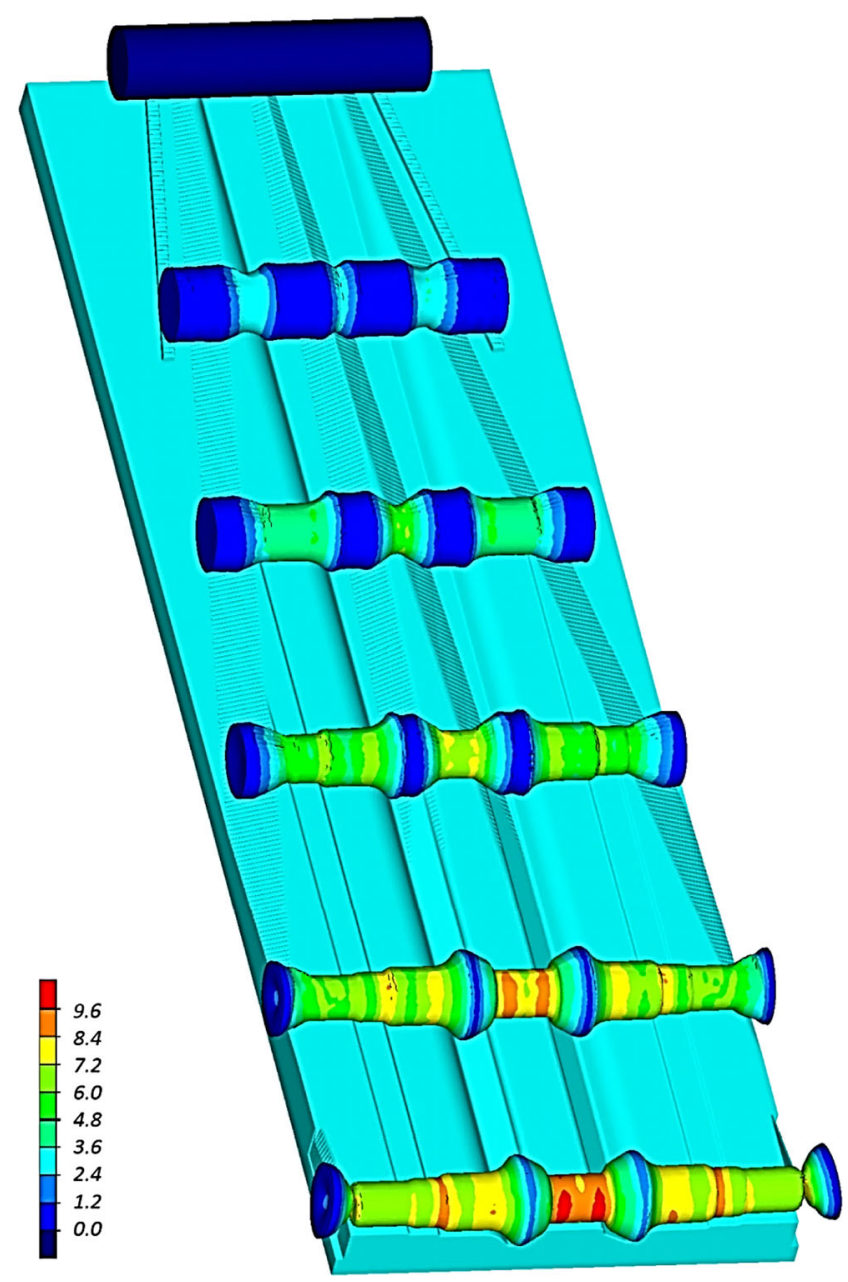

Fig. 11 Progression of the shape of drive shafts produced by MWCR and the distribution of effective strains

\section{Multi-wedge cross rolling}

In MWCR, the material is formed by all wedges at the same time, which significantly reduces the tool length. Nonetheless, it is possible to employ a different solution in which the tool length remains unchanged, yet the number of parts simultaneously formed is increased. This solution was applied in the analyzed case. Specifically, it was assumed that the forming process would be performed in two stages, in which two shafts connected to each other by thin shanks are formed at the same time. Here, it is possible to apply rolling with upsetting, which enables the use of the billet with a smaller diameter. Under this assumption, the billet is described by a diameter of $48 \mathrm{~mm}$ and a length of $204 \mathrm{~mm}$ and has a volume of $369,150 \mathrm{~mm}^{3}$. Although with this process, two parts are formed at the same time; material losses per one shaft are merely $21,940 \mathrm{~mm}^{3}$, which is $13.5 \%$ of the volume of the part.
Fig. 10 Schematic design of the wedge tools used for producing drive shafts by MWCR 
Fig. 12 Distribution of the produced by MWCR effective strains in drive shafts

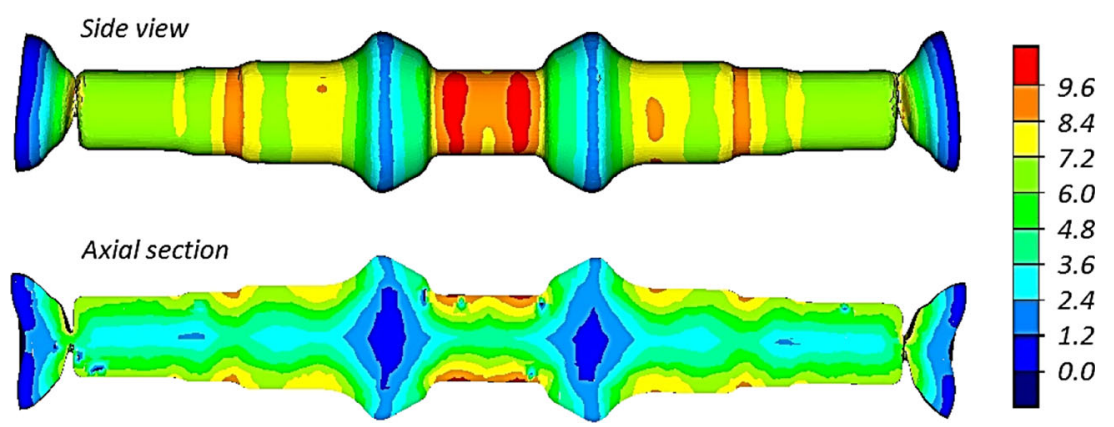

Fig. 13 Distribution of the damage function (according to Cockroft-Latham criterion) in drive shafts produced by MWCR

Fig. 14 Distribution of the temperature (in ${ }^{\circ} \mathrm{C}$ ) in drive shafts produced by MWCR
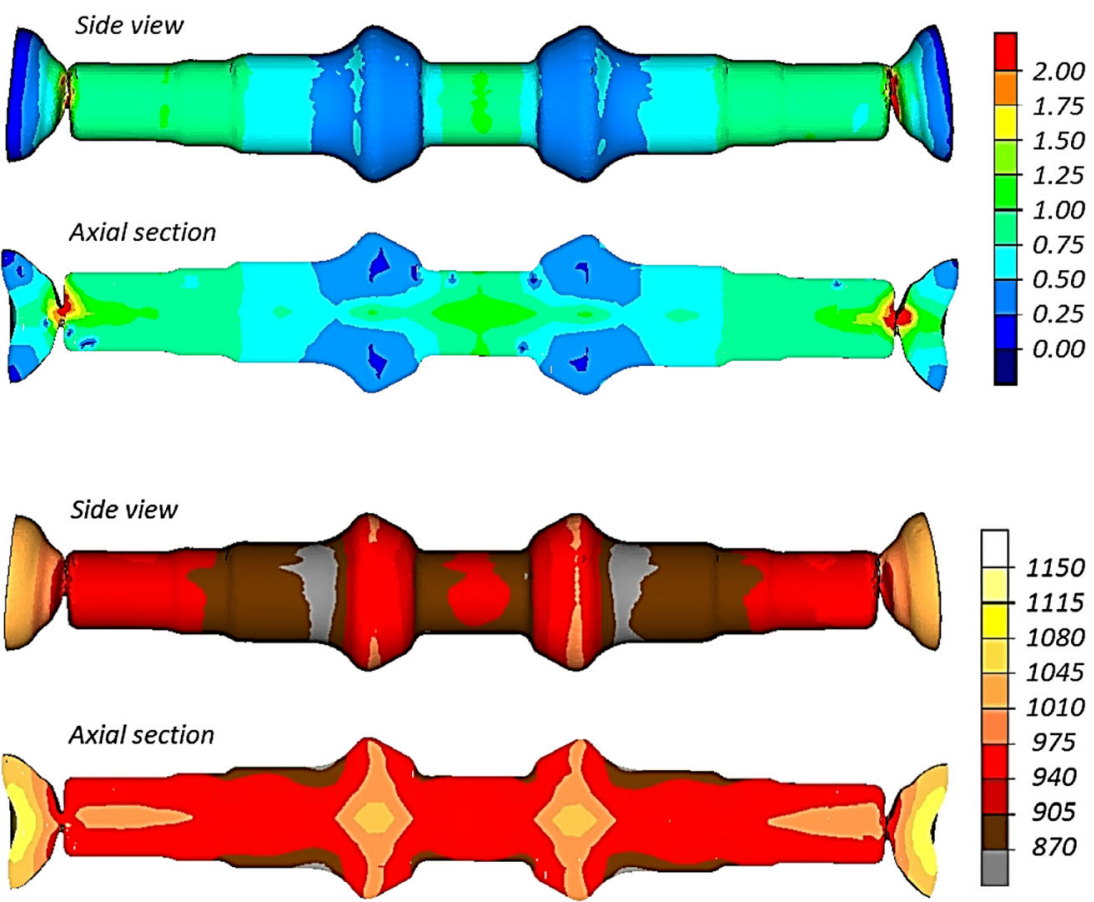

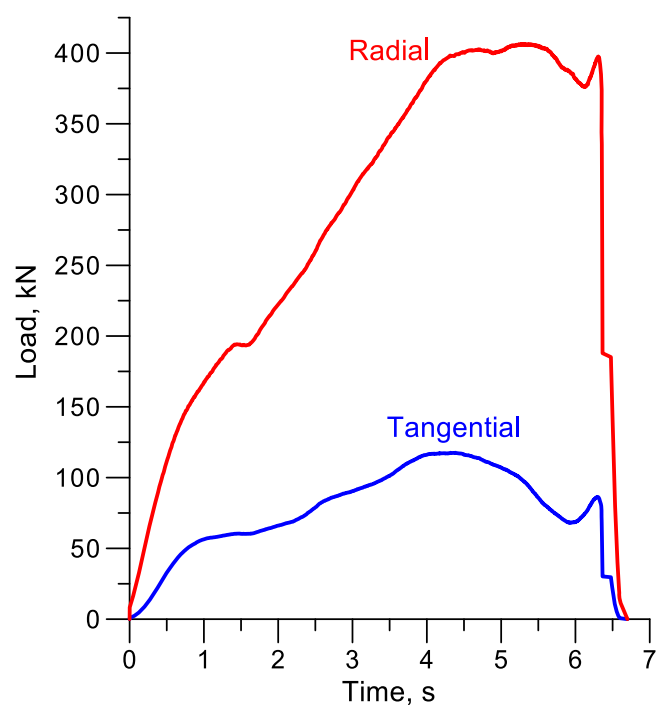

Fig. 15 Variations in the rolling forces when producing drive shafts by MCWR

\subsection{Tools for MWCR}

The tool segment used for producing drive shafts by MWCR is shown in Fig. 10. In the proposed solution, the parts are formed by three wedges at the same time. In contrast to the standard MWCR method (Fig. 2b), the end wedges are not inclined at an angle $\Theta$ to the direction of tool displacement. Consequently, it is possible to upset the shaft's region located between wedges 1 and 2 (Fig. 10), i.e., from the diameter of 48 to $60.5 \mathrm{~mm}$. As a result of the reduction in billet diameter, the reduction ratio $\delta$ decreases from 2.0 (standard CWR) to 1.65 , which, in turn, means that the end steps of the shaft can be formed in one pass. Figure 10 also specifies values of the spreading and forming angles describing individual wedges. As for the central wedge, the forming angle is set to $35^{\circ}$, and the spreading angle is set to $2.6^{\circ}$, both values enabling material upsetting. In turn, the side wedges are described by the values which are typical of the $\alpha$ and $\beta$ angles. 


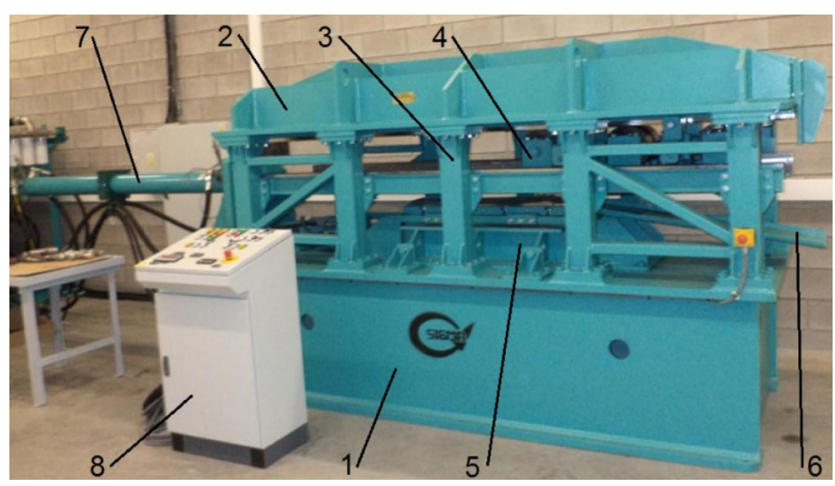

Fig. 16 Flat-wedge rolling mill available at the Lublin University of Technology. 1-lower frame, 2-upper frame, 3-connecting pillars, 4 - slide with wedge tool, 5- bottom table with wedge tool, 6 - chute, 7-hydraulic cylinder, 8 - control desk

\subsection{Numerical simulation of the MWCR process}

As above, the proposed solution was verified by a numerical simulation performed using the same parameters as in the classical CWR method. The only changes pertained to the tools and the billet.

As illustrated in Fig. 11, the MWCR process for forming two shafts at the same time proceeds correctly, leading to the production of a semi-finished part with the desired shape. Due to the action of the central tool, the material is upset to a degree required to form the largest step. At the final stage of the process, the shafts undergo sizing. After that, the end scrap material is cut off by the side cutters. Thereby, produced shafts are connected by means of the shorter shanks, and their separation requires an additional cutting operation using, e.g., a cut-off machine.

Fig. 12 shows the distribution of effective strains in the shafts produced by the MWCR method. Here, the strains are also arranged in ring-like layers and are the highest near the surface exposed to the action of the friction forces. At the same time, however, it can be observed that the location of the highest strains has changed. In CWR, the highest strains occur at the end of the long shank of the shaft; while in MWCR they occur in the short shank. The observed

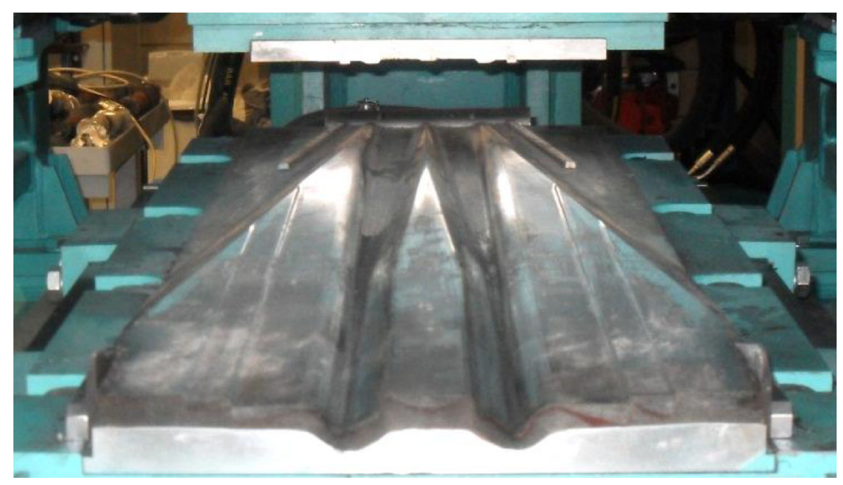

Fig. 17 Wedge tool used in the MWCR process for producing dive shafts

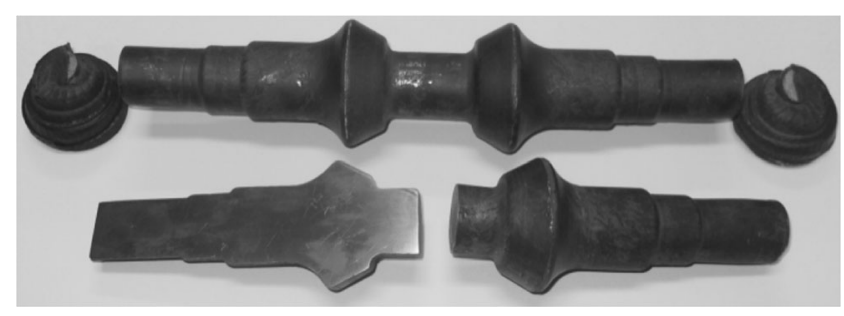

Fig. 18 Drive shafts produced by MWCR

difference results from intensive plastic working of the material, which is typical of rolling processes with upsetting.

Examining the distribution of the damage function (Fig. 13) in the shafts produced by MWCR, it can be observed that the highest values of this function occur in the spot where the bottom crops are joined to the long shaft shanks. It is there where material cracking may occur. This is however desired, as it will lead to cutting off the end scrap material. Comparing the plots of the damage function obtained in CWR and MWCR, it can be observed that the risk of material cracking is lower in MWCR than in the classical CWR. This probably results from the cross sectional reduction in the material due to the use of a smaller diameter billet.

The observed decrease in the temperature of the material in MWCR (Fig. 14) is similar to the decrease observed in the previous case (Fig. 8). This is logical, as the parameters applied in both cases are identical. Particularly, the time of contact between the material and the tools, when heat is being carried away from the material, is the same.

The variations in the forces (tangential and radial) in MWCR (Fig. 15) are very similar to those observed for the classical CWR (Fig. 9). Naturally, absolute values of the forces are higher, which result from the fact that two parts are formed at the same time. However, the results of the forces in both analyzed cases demonstrate that in MWCR, the tangent force is $157.9 \%$ of the force obtained in the classical process, while the radial force is $177.1 \%$ of that observed in CWR. This means that the MWCR process is less energyconsuming. Based on the results, it is assessed that the energy required for forming a shaft by MWCR is by $21 \%$ lower than that required in the classical CWR process.

\subsection{Experimental tests of the MWCR process}

Due to economic reasons, the experimental tests of forming drive shafts were only performed by the MWCR method. The choice of this method was dictated by the numerical results.

The experiments were performed using a flat-wedge rolling mill designed and constructed at the Lublin University of Technology (Fig. 16). The machine enables forming axisymmetric parts with a diameter of up to $70 \mathrm{~mm}$ and a length of up to $310 \mathrm{~mm}$. It is equipped with a hydraulically-driven slide which moves during rolling with a velocity of $0.3 \mathrm{~m} / \mathrm{s}$. The 
maximum force of the tool ensured by this rolling mill is $200 \mathrm{kN}$

The rolling mill consisted of two identical wedge tools; one of them is shown in Fig. 17. The tools were made of steel tools for hot forming in accordance with the schematic design shown in Fig. 10.

The parameters applied in the experiments were the same as those used for the numerical analysis. The billet was heated in a chamber furnace to a temperature of $1150^{\circ} \mathrm{C}$. Next, it was put on the fixed lower tool and the forming process was started.

Drive shafts produced in the rolling tests by MWCR have a correct shape and their dimensions agree with those shown in Fig. 1. Moreover, they are free from both surface and structural defects. Figure 18 shows examples of the produced shafts (scrap material included) after the rolling process and after cutting by the cut-off machine.

\section{Conclusions}

The results demonstrate that drive shafts can be produced by the cross wedge rolling method. In addition, it has been found that performing the MWCR process in two stages is more effective. Compared to the classical CWR process, the proposed MWCR method offers a number of advantages including the following:

- $\quad$ higher efficiency (by two times),

- reduced material losses (MCWR-material losses are $13.5 \%$; classical CWR-32.6\%),

- reduced energy consumption of producing a shaft (by approx. 21\%), and

- lower probability of cracking inside shafts.

Open Access This article is distributed under the terms of the Creative Commons Attribution 4.0 International License (http:// creativecommons.org/licenses/by/4.0/), which permits unrestricted use, distribution, and reproduction in any medium, provided you give appropriate credit to the original author(s) and the source, provide a link to the Creative Commons license, and indicate if changes were made.

\section{References}

1. Pater Z (2014) Cross-wedge rolling. Comprehensive Materials Processing 3:211-279. doi:10.1016/B978-0-08-096532-1.00315-0
2. Zhao J, Lu L (2012) The application of multi-wedge cross wedge rolling forming long shaft technology. Appl Mech Mater 101-102: 1002-1005. doi:10.4028/www.scientific.net/AMM.101-102.1002

3. Hu B, Shu X, Yu P, Peng W (2014) The strain analysis at the broadening stage of the hollow railway axle by multi-wedge cross wedge rolling. Appl Mech Mater 494-495:457-460. doi:10.4028 /www.scientific.net/AMM.494-495.457

4. Wensheng Y, Zhonglei W, Baojun S, Gang C (2012) Theoretical analysis of the displacement on the end-section of the rolled parts for multi-wedge cross wedge rolling. Adv Mater Res 538-541:1162-1169. doi:10.4028/www.scientific. net/AMR.538-541.1162

5. Zhao J, Shu X, Hu Z (2005) Study of stress distribution of forming slandering of automobile semi-axes with multi-wedge cross wedge rolling by FEM simulation. ICMIT 2005: Control systems and robotics Pts 1 and 2 6042:4247

6. Jing Z, Xuedao S, Zhenghuan H (2007) Computer aided design for cross wedge rolling tools of automobile semi-axes. J Mater Process Technol 187-188:41-45. doi:10.1016/j. jmatprotec.2006.11.189

7. Shu X, Li Z, Zu W (2012) Bending analysis and measures of the forming of automobile semi-axle on cross-wedge rolling with multi-wedge. Appl Mech Mater 184-185:75-79. doi:10.4028 /www.scientific.net/AMM.184-185.75

8. Sun B, Zeng X, Shu X, Peng W, Sun P (2012) Feasibility study on forming hollow axle with multi-wedge synchrostep by cross wedge rolling. Appl Mech Mater 201-202:673-677. doi:10.4028/www. scientific.net/AMM.201-202.673

9. Shu X, Wei X, Li C, Hu Z (2010) The influence rules of stress about technical parameters on synchronous rolling railway axis with multi-wedge cross-wedge rolling. Appl Mech Mater 37-38:14821488. doi:10.4028/www.scientific.net/AMM.37-38.1482

10. Pater Z (2013) Multi-wedge cross rolling of balls. J Iron Steel Res Int 20:46-50. doi:10.1016/S1006-706X(13)60175-2

11. Jia Z, Zhou J, Ji J et al (2013) Influence analysis of area reduction for necking in twice-stage cross wedge rolling. Int J Adv Manuf Technol 66:1407-1413. doi:10.1007/s00170-012-4418-3

12. Liu G, Zhong Z, Shen Z (2014) Influence of reduction distribution on internal defects during cross wedge-rolling process. Procedia Engineering 81:263-267. doi:10.1016/j.proeng.2014.09.161

13. Li Q (2003) Characterization of failure mechanisms in cross wedge rolling. Dissertation, University of Pittsburgh

14. Bulzak T, Pater Z, Tomczak J (2015) Numerical modelling of a new cross-wedge rolling technique. Hutnik-WH 82:573-576. doi:10.15199/24.2015.8.21

15. Pater $Z$ (1999) Numerical simulation of the cross wedge rolling process including upsetting. J Mater Process Technol 92-93:468473. doi:10.1016/S0924-0136(99)00231-9

16. Tofil A, Tomczak J, Pater Z (2013) Cross wedge rolling with upsetting. Arch Metall Mater 58:1191-1196. doi:10.2478/amm-20130150

17. Zhou J, Yu Y, Zeng Q (2014) Analysis and experimental studies of internal voids in multi-wedge cross wedge rolling stepped shaft. Int J Adv Manuf Technol 72:1559-1566. doi:10.1007/s00170-0145768-9 